\title{
Ultrasound-guided Transmuscular Quadratus Lumborum Block With Depot Steroids in the Management of Abdominal Myofascial Pain SYNDROME
}

\author{
Gopinath Niraj, FFPMRCA
}

Background: Trigger point injection is the current standard in the management of abdominal myofascial pain syndrome (AMPS). However, multiple trigger point injections can cause significant discomfort and there is a possibility of missing trigger points resulting in a reduced efficacy of trigger point treatment. Recently, abdominal wall blocks have been reported in the management of chronic abdominal wall pain. Transmuscular quadratus lumborum block (TQLB) is a novel abdominal wall block.

Objective: The report describes the role of the ultrasound-guided TQLB with depot steroids in the management of AMPS.

Study Design: Prospective case series.

Setting: Tertiary pain medicine clinic in a University Hospital.

Methods: Adult patients with AMPS under the care of a single physician were offered TQLBs with a mixture of local anaesthetic and depot methylprednisolone instead of multiple trigger point injections as a part of an on-going prospective longitudinal audit into the management of
AMPS. Patients completed brief pain inventory questionnaire at baseline and at 12 weeks postprocedure.

Results: Thirty patients underwent TQLB. All patients reported complete absence of pain within 15 minutes of the block and sensory testing revealed extensive hypoaesthesia extending from thoracic T6 to T12 anteriorly. Clinically significant benefit at 12 weeks was reported by $36 \%$ of patients, with $60 \%(18 / 30)$ of the patients preferring to receive the novel intervention instead of multiple trigger point injections. None of the patients reported post-procedural flare up.

Limitations: Open label case series in a small cohort.

Conclusion: The prospective series in a limited cohort suggests that TQLB with depot steroids could play a role in the management of AMPS.

Key words: Abdominal myofascial pain syndrome, transmuscular quadratus lumborum block, trigger point treatment, nonspecific abdominal pain, viscerosomatic convergence
Abdominal myofascial pain syndrome (AMPS) is a poorly recognised cause of chronic abdominal wall pain (CWAP) (1). Failure to correctly diagnose and manage AMPS can result in unnecessary investigations, including surgery and unsatisfactory outcomes with significant health care costs (2-4).

Author for correspondence: Gopinath Niraj, FFPMRCA

Address: Consultant, Department of Anaesthesia and Pain Medicine, Honorary Senior Lecturer, University of Leicester, Clinical Research Unit in Pain Medicine, University Hospitals of Leicester, Gwendolen Road, Leicester, LE5 4PW

E-mail: nirajgopinath@yahoo.co.uk
AMPS develops as a result of trigger points in the abdominal musculature. Trigger points in the abdominal wall muscles can develop as a result of both central and peripheral sensitisation caused by underlying visceral inflammation. This phenomenon is termed viscerosomatic convergence $(1,2,5,6)$. Initial diagnosis is by eliciting Carnett's sign on clinical examination $(1,7)$. The diagnosis is usually confirmed on having a positive response to trigger point injection (TPI) $(1,3,8,9)$. TPI is performed using either a landmark technique (blind) or under ultrasound guidance $(9,10)$. Often patients require injections into multiple trigger points and this could result in significant discomfort during the proce- 
dure as well as prolonged post procedural flare up (1). Abdominal wall blocks including transversus abdominis plane (TAP) have been reported in the management of CAWP (11-14). Transmuscular quadratus lumborum block (TQLB) is a novel abdominal wall block where the local anaesthetic agent is deposited in a fascial plane between the quadratus lumborum (QL) and psoas major muscles (15). TQLB has been reported to result in an extensive thoraco-lumbar sensory block $(16,17)$. The author presents the first report on the use of ultrasound guided TQLB with a mixture of local anaesthetic agent and depot steroid in the management of AMPS.

\section{METHODS}

Adult patients diagnosed with AMPS under the care of a single pain physician based in a tertiary pain medicine service were offered TQL block with a mixture of local anaesthetic and depot steroid as an alternative to multiple TPIs as a part of an on-going prospective audit into the management of AMPS (1). Diagnostic criteria for AMPS included (1):

\section{History}

Constant dull achy pain in the abdomen with intermittent sharp flare-ups, referred to the flank, groin or the leg; aggravated on activity, relieved on curling up and a past history of visceral inflammation.

\section{Examination}

Tender trigger points not localized to the lateral border of the rectus abdominis muscle, absence of cutaneous allodynia or hypoaesthesia and a positive Carnett's sign.

TQLB is a recently described novel abdominal wall block with an extensive sensory block $(15,16)$. Abdominal wall blocks, including TAP blocks, are currently used in the management of AMPS at the author's centre. The author has experience of performing abdominal wall blocks, including TQLB in the perioperative setting (17). Patients with multiple trigger points ( $>5$ triggers) who had previously undergone ultrasound guided TPI were offered the novel block instead of multiple TPIs.

The objective was to identify if TQLB with depot steroids could reduce patient discomfort, reduce incidence of post procedural flare up, and provide an improved therapeutic benefit at 12 weeks following treatment. Informed consent was obtained prior to the procedure. Patients were given detailed information on the technique, potential risks and the objective for offering a novel procedure (reduced discomfort). All patients provided written consent for their de-identified data to be used for analysis and for publication in a peer reviewed journal.

Patients received ultrasound guided TQLB with a mixture of local anaesthetic and depot steroids. Patients with unilateral TQLB received $10 \mathrm{~mL}$ of $0.5 \%$ levo-bupivacaine and $60 \mathrm{mg}$ of depot methylprednisolone. Patients having bilateral TQLB received $10 \mathrm{~mL}$ of $0.5 \%$ levo-bupivacaine and $40 \mathrm{mg}$ of depot steroid on each side. Dermatomal sensory testing with ethyl chloride spray was performed at 15 minutes post-procedure. Following TQLB, a specialist nurse in pain medicine followed up the patients over telephone at 12 weeks.

Patients completed Brief Pain Inventory Short Form (BPI-SF) and quality of life (EQ 5D) questionnaires at baseline and at 12 weeks after treatment (returned by post). Clinically significant pain relief was defined using the 'pain at its worst in the last 24 hours' construct in the BPI-SF questionnaire. This 11-point pain intensity Numeric Rating Scale (NRS11) has been found to have the strongest relationship with the pain interference scale $(18,19)$. Following IMMPACT recommendations (Initiative on Methods, Measurement, and Pain Assessment in Clinical Trials), a 2-point change (30-36\%) at 12 weeks post treatment was considered as successful therapeutic intervention (20). Missing data was imputed using the 'last-observation-carried-forward' method.

\section{Technique}

The patient is positioned in the lateral position on a flexed operating table (open nephrectomy position). The skin is prepared with $2 \%$ chlorhexidine solution and sterile drapes placed to create an aseptic field. A high frequency $(5-10 \mathrm{MHz})$ ultrasound probe (S Nerve, Sonosite, Inc. Bothwell, USA) is placed transversely in the anterior abdominal wall to identify the rectus muscle and then, the 3 lateral abdominal muscles (external oblique, internal oblique, and transversus abdominis). The probe is gradually 
moved posterolaterally to identify the QL muscle and thereafter, the plane between the QL muscle and the psoas major muscle (Fig. 1). A $100 \mathrm{~mm}$ needle (Stimuplex, B Braun) is introduced in the plane of the ultrasound beam and directed towards the plane traversing the QL muscle. On entering the fascial plane, $5 \mathrm{~mL}$ of normal saline $0.9 \%$ is injected to open the plane (saline hydro-dissection). The injectate can be observed spreading in the TQL plane as a dark oval shape (Fig. 2). Thereafter, the mixture of local anaesthetic and depot steroid is injected. The procedure is repeated on the other side if required.

\section{RESULTS}

Over a 9-month period, 30 patients with AMPS were offered TQLB with depot steroids instead of repeat multiple TPIs. All patients had over 5 trigger points and had previously received TPI with depot steroids. The novel treatment was performed only after the pain had returned to the baseline following TPI. Four patients had features of postsurgical neuropathic pain (liver resection, mesh hernia repair, laparoscopic appendectomy) in addition to myofascial trigger points. Two patients were lost to follow-up.

Ultrasound guided TQLB was performed in all patients. Twenty-one patients required a unilateral block, while 9 patients received bilateral TQLB. TQLB provided complete relief within 15 minutes in all patients. Sensory testing with ethyl chloride spray revealed hypoaesthesia extending from the thoracic T6 to T12 dermatome in the anterior abdominal wall. Dermatomal testing along the lateral and posterior abdominal wall revealed hypoaesthesia extending posteriorly over the QL muscle. There was no change in sensation over the lumbar dermatomes.

All patients tolerated the procedure under local anaesthetic and did not require additional sedation. All patients found TQLB to be a superior procedure to tolerate.

Clinically significant pain relief at 3 months following TQLB was reported by $36 \%$ (11/30) of the responders (Table 2). Relief was short lived ( $<2$ weeks) in 3 patients with postsurgical neuropathic scar pain. They reported superior benefit with TPIs.

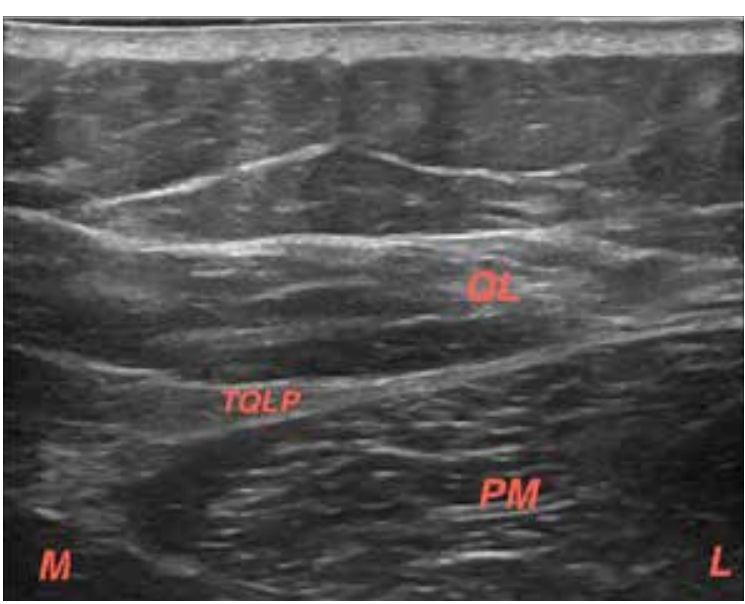

Fig. 1. The transmuscular quadratus lumborum plane between the QL and psoas major muscles.

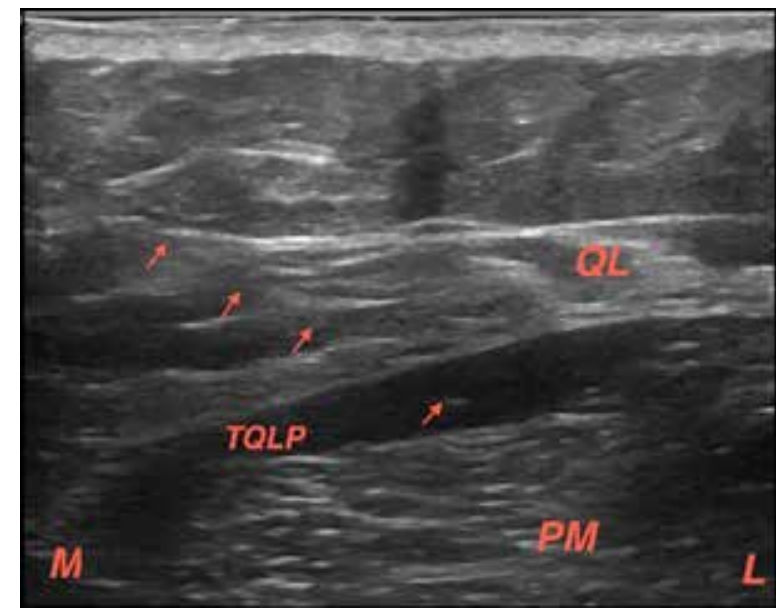

Fig. 2. Hydro dissection of the transmuscular quadratus lumborum plane with normal saline. Arrows indicate the needle.

Trigger points were localized in the lower quadrant on the abdomen in a majority of patients $(25 / 30)$. It was observed that patients who reported the most durable benefit had their pain localized to the lower abdomen. Five patients with pain localized in the upper quadrant reported transient benefit with TQLB when compared to TPI.

Quality of life (EQ-5D) scores are reported based on the Pareto Classification of Health Change (PCHC) (21). PCHC classifies change in health following an 
Table 1. Patient characteristics and duration of relief following TQLB.

\begin{tabular}{|c|c|c|c|c|c|c|}
\hline Patient ID & $\begin{array}{l}\text { Gender, Age } \\
\text { (year) }\end{array}$ & $\begin{array}{l}\text { Duration of } \\
\text { pain (year) }\end{array}$ & $\begin{array}{c}\text { Unilateral / } \\
\text { Bilateral }\end{array}$ & $\begin{array}{l}\text { Primary visceral } \\
\text { inflammation }\end{array}$ & $\begin{array}{c}\text { Duration of } 30 \% \\
\text { Relief with } \\
\text { TQLB }\end{array}$ & $\begin{array}{l}\text { Superior } \\
\text { Treatment }\end{array}$ \\
\hline 1 & $\mathrm{~F}, 66$ & 10 & $\mathrm{U}$ & Pancreas & 5 weeks & TPI \\
\hline 2 & $\mathrm{~F}, 32$ & 2 & $\mathrm{U}$ & Endometriosis & 12 weeks & TQLB \\
\hline 3 & $\mathrm{~F}, 24$ & 5 & $\mathrm{U}$ & GU Tract & 8 weeks & TQLB \\
\hline 4 & $\mathrm{~F}, 23$ & 1 & B & GU Tract & 12 weeks & TQLB \\
\hline 5 & M, 29 & 1 & $\mathrm{U}$ & GU Tract & 8 weeks & TQLB \\
\hline 6 & F, 38 & 3 & $\mathrm{U}$ & Appendicitis & 5 weeks & TPI \\
\hline 7 & $\mathrm{M}, 64$ & 5 & $\mathrm{U}$ & GU Tract & 12 weeks & TQLB \\
\hline 8 & $F, 34$ & 1 & B & GU Tract & 8 weeks & TQLB \\
\hline 9 & F, 33 & 2 & B & GU Tract & 12 weeks & TQLB \\
\hline 10 & $F, 63$ & 2 & $\mathrm{U}$ & Biliary & 12 weeks & TQLB \\
\hline 11 & $\mathrm{~F}, 59$ & 3 & $\mathrm{U}$ & Biliary & 5 weeks & TQLB \\
\hline 12 & $\mathrm{~F}, 35$ & 2 & $\mathrm{U}$ & Biliary & 5 weeks & TQLB \\
\hline 13 & F, 27 & 5 & $\mathrm{U}$ & GU Tract & 6 weeks & TQLB \\
\hline 14 & $\mathrm{M}, 30$ & 4 & $\mathrm{U}$ & Pancreas & 8 weeks & TQLB \\
\hline 15 & F, 39 & 1 & $\mathrm{U}$ & Biliary & 12 weeks & TPI \\
\hline 16 & F, 48 & 1 & $\mathrm{U}$ & Biliary & 12 weeks & TQLB \\
\hline 17 & $\mathrm{M}, 54$ & 8 & $\mathrm{U}$ & Pancreas & 1 week & TPI \\
\hline 18 & F, 28 & 3 & B & Endometriosis & 1 week & TPI \\
\hline 19 & F, 53 & 2 & $\mathrm{U}$ & Liver Resection & 1 week & TPI \\
\hline 20 & M, 55 & 2 & $\mathrm{U}$ & GU Tract & LFU & LFU \\
\hline 21 & $\mathrm{~F}, 30$ & 1 & $\mathrm{~B}$ & Pancreas & 4 weeks & TPI \\
\hline 22 & $\mathrm{~F}, 41$ & 4 & $\mathrm{U}$ & Endometriosis & 1 week & TPI \\
\hline 23 & $\mathrm{M}, 50$ & 4 & $\mathrm{U}$ & GU Tract & 12 weeks & TQLB \\
\hline 24 & $\mathrm{~F}, 72$ & 5 & B & GU Tract & 12 weeks & TQLB \\
\hline 25 & F, 32 & 4 & $\mathrm{U}$ & Endometriosis & 12 weeks & TQLB \\
\hline 26 & $\mathrm{~F}, 43$ & 4 & $\mathrm{U}$ & Unclear & LFU & LFU \\
\hline 27 & F, 29 & 3 & B & Endometriosis & 4 weeks & TPI \\
\hline 28 & F, 50 & 1 & B & Peritonitis/surgery & 5 weeks & TQLB \\
\hline 29 & M, 36 & 16 & $\mathrm{~B}$ & GU Tract & 5 weeks & TQLB \\
\hline 30 & $\mathrm{~F}, 46$ & 3 & $\mathrm{U}$ & Unclear & 4 weeks & TPI \\
\hline
\end{tabular}

intervention into 4 categories: health is better, same, worse, or mixed (better in one dimension, worse in another dimension) (Table 1).

TQLB was found to be a superior technique for providing pain relief by $60 \%$ of patients $(18 / 30)$. Postprocedural flare up in pain lasting over 48 hours was reported by $39 \%(12 / 30)$ of patients following TPI, while none of the patients with TQLB reported post procedural flare up.

\section{DISCUSSION}

The author presents the first report on the use of ultrasound guided TQLB in the management of AMPS. TQLB with depot steroids provided on going relief at 12 weeks in $36 \%$ patients in this series. The current standard intervention in the diagnosis and management of AMPS is TPI $(1-4,9)$. Patients usually require multiple injections $(1,2,10)$. This can result in significant distress, increases risk of visceral injury, especially if the procedure is performed using 
Table 2. Brief pain inventory short form (BPI-SF) scores and quality of life (Euro-QoL) at baseline and at 12 weeks post TQLB and trigger point injection.

\begin{tabular}{|c|c|c|c|c|c|c|}
\hline Patient ID & $\begin{array}{c}\text { Baseline Worst } \\
\text { Pain Score in } 24 \mathrm{~h} \\
\text { TQLB }\end{array}$ & $\begin{array}{c}12 \text { weeks Worst } \\
\text { Pain Score in } 24 \mathrm{~h} \\
\text { TQLB }\end{array}$ & $\begin{array}{c}12 \text { weeks } \\
\text { EQ-5D } \\
\text { TQLB }\end{array}$ & $\begin{array}{c}\text { Baseline Worst } \\
\text { Pain Score in } 24 \mathrm{~h} \\
\text { TPI }\end{array}$ & $\begin{array}{c}12 \text { weeks Worst } \\
\text { Pain Score in } 24 \mathrm{~h} \\
\text { TPI }\end{array}$ & $\begin{array}{c}12 \text { weeks } \\
\text { EQ-5D } \\
\text { TPI }\end{array}$ \\
\hline 1 & 9 & 8 & Same & 10 & 9 & Same \\
\hline 2 & 6 & 2 & Better & 5 & 7 & Same \\
\hline 3 & 9 & 9 & Same & 9 & 8 & Same \\
\hline 4 & 6 & 2 & Better & 9 & 4 & Better \\
\hline 5 & 8 & 7 & Same & 10 & 9 & Worse \\
\hline 6 & 7 & 7 & Worse & 10 & 3 & Better \\
\hline 7 & 6 & 3 & Better & 10 & 4 & Better \\
\hline 8 & 8 & 7 & Better & 9 & 8 & Same \\
\hline 9 & 8 & 6 & Better & 7 & 7 & Better \\
\hline 10 & 5 & 0 & Better & 8 & 7 & Worse \\
\hline 11 & 8 & 7 & Worse & 8 & 9 & Same \\
\hline 12 & 10 & 8 & Same & 10 & 10 & Worse \\
\hline 13 & 9 & 7 & Same & 8 & 8 & Better \\
\hline 14 & 9 & 7 & Better & 7 & 8 & Better \\
\hline 15 & 9 & 10 & Same & 10 & 7 & Better \\
\hline 16 & 8 & 5 & Better & 9 & 7 & Better \\
\hline 17 & 9 & 9 & Worse & 9 & 0 & Better \\
\hline 18 & 8 & 10 & Worse & 10 & 6 & Better \\
\hline 19 & 8 & 9 & Same & 10 & 9 & Same \\
\hline 20 & 5 & LFU & Same & 6 & 5 & LFU \\
\hline 21 & 6 & 6 & Same & 6 & 0 & Same \\
\hline 22 & 9 & 9 & Same & 8 & 8 & Same \\
\hline 23 & 8 & 2 & Better & 8 & 5 & Better \\
\hline 24 & 8 & 6 & Better & 8 & 4 & Same \\
\hline 25 & 10 & 6 & Better & 6 & 4 & Same \\
\hline 26 & 8 & LFU & Same & 8 & 9 & LFU \\
\hline 27 & 7 & 6 & Better & 8 & 7 & Same \\
\hline 28 & 7 & 7 & Same & 8 & 8 & Better \\
\hline 29 & 9 & 9 & Same & 10 & 9 & Same \\
\hline 30 & 8 & 8 & Same & 6 & 2 & Better \\
\hline
\end{tabular}

$\mathrm{LFU}=$ lost to follow up, TQLB $=$ transmuscular quadratus lumborum block, TPI = trigger point injection

a landmark technique, and there is a possibility of missing trigger points in the muscle. Myofascial trigger points have been described in various muscles that form the anterior and posterior abdominal wall. TQLB involves a single ultrasound guided injection and it has been reported to provide sensory block of the entire hemi-abdomen (15-17).

An alternative technique recommended in the management of CWAP is the TAP block (11-14). Two types of TAP blocks have been described (22-24). The subcostal TAP block covers the thoracic dermatomes from T6 to T10. Subcostal TAP block does not reliably cover dermatomes below T10 $(22,23)$. The posterior TAP block provides sensory block to the lower abdomen (dermatomes T10-L1). Posterior TAP block does not reliably cover dermatomes above T10 dermatome. The presence of this watershed 
zone at T10 dermatome has been confirmed by both anatomical and clinical studies $(24,25)$. Thus, in the presence of trigger points in both the upper and lower abdomen, a single TAP block will not cover the area involved in pain generation. Ten patients in our series with unilateral abdominal pain had trigger points in the upper and lower abdomen. The sensory block from TAP blocks does not extend beyond the anterior axillary line. Thus, posterior TAP block will not cover trigger points in the QL muscle. Seven patients in this series had trigger points in the QL muscle. It can be challenging to perform TAP blocks in patients who have had surgical procedures on the abdomen as the fascial planes can be disrupted. Two patients in this series had surgical procedures with tissue plane disruption (pancreatic surgery, liver resection).

TQLB has been reported to provide extensive sensory blockade of the hemi-abdomen and is performed away from the potential trigger points. It can cover trigger points in the posterior abdominal wall, including the QL muscle. There is evidence that shows the extent of sensory blockade following TQLB $(16,17)$. In the current series, sensory testing revealed hypoaesthesia extending from the thoracic T6 to T12 dermatomes. This observation confirms the paravertebral site of action.

Current therapeutic standard in the management of AMPS is TPI with a mixture of local anaesthetics and depot steroids. The average duration of relief following abdominal TPI is reported to range from 6 to 12 weeks $(9,26)$. TQLB provided on going relief at 12 weeks in $36 \%$ of patients. This is similar to the $43 \%$ reported by Alnahhas et al (9) in their series following ultrasound guided TPI. Patients with features of neuropathic pain may obtain a transient relief following TQLB with steroids. Patients with trigger points in the upper abdomen reported transient relief following TQLB.

AMPS is a common and often unrecognized clinical entity that can utilise significant health care costs $(2,3)$. This report in a limited cohort suggests ultrasound guided TQLB as an alternative technique to TPI in the management of AMPS. Initial findings suggest that patients with pain localized to the lower abdomen including the flank may benefit from TQLB. Patients with pain localized to the upper abdomen may receive greater benefit from either TPI or if the fascial planes are preserved, a subcostal TAP block (14). Patients with co-existent post surgical neuropathic pain may benefit from targeted injection of depot steroid into the muscle. A major advantage of utilising abdominal field blocks like TQLB and subcostal TAP include a definitive visible end point (opening of the facial planes) when compared to TPIs (Fig. 2). This may enhance standardization for future studies in the management of AMPS. Further work is required to confirm the therapeutic benefit of TQLB in the management of AMPS.

\section{REFERENCES}

1. Niraj G. Pathophysiology and management of abdominal myofascial pain syndrome (AMPS): A 3-year prospective audit of a management pathway in 120 patients. Pain Med 2018 (Epub ahead of print).

2. Constanza CD, Longstreth GF, Liu AL. Chronic abdominal wall pain: Clinical features, health care costs, and long-term outcome. Clin Gastroenterol Hepatol 2004; 2:395-399.

3. Niraj G, Chaudhri S. Prospective audit of a pathway for in-patient pain management of chronic abdominal pain: A novel and cost effective strategy. Pain Med 2018; 19:589-597.

4. Johlin FC, Buhac J. Myofascial pain syndromes: An important source of abdominal pain for refractory abdominal pain. Gastroenterology 1996; 110: A808.

5. Jarrell J. Myofascial dysfunction in the pelvis. Curr Pain Headache Rep 2004; 8:452-456.

6. Giamberardino MA, Affaitati G, lezzi S, Vecchiet L. Referred muscle pain and hyperalgesia from viscera. J Musculoskelet Pain

1999; 7:61-69.

7. Carnett JB. Intercostal neuralgia as a cause of abdominal pain and tenderness. Surg Gynecol Obstet 1926; 42:625-632.

8. Suleiman S, Johnson DE. The abdominal wall: An overlooked source of pain. Am Fam Physician 2001; 64:431-438.

9. Alnahhas MF, Oxentenko S, Locke GR, Hansel S, Schleck CD, Zinsmeister AR, Farrugia G, Grover M. Outcomes of ultrasound guided trigger point injection for abdominal wall pain. Dig Dis Sci 2016; 61:572-577.

10. Niraj G, Collett BJ, Bone M. Ultrasound guided trigger point injection: first description of changes visible on ultrasound scanning in the muscle containing the trigger point. Br J Anaesth 2011; 107:474-475.

11. Soliman LM, Narouze S. Ultrasound-guided transversus abdominis plan block for the management of abdominal pain: An alternative to differential epidural block. Tech Reg Anesth Pain Manag 2009; 13:117-120. 
12. Guirguis MN, Abd-Elsayed AA, Girgis G, Soliman LM. Ultrasound-guided transversus abdominis plane catheter for chronic abdominal pain. Pain Pract 2013; 13:235-238.

13. Takimoto K. Transversus abdominis plane block for chronic abdominal pain in a critically ill patient. Anaesth Intensive Care 2014; 42:809-810.

14. Niraj G. Subcostal transversus abdominis plane (STAP) block with depot steroids in the management of upper abdominal myofascial pain syndrome (AMPS). J Anesth Surg 2017; 4:1-4.

15. Borglum J, Moriggi B, Jensen K, Lonnqvist PA, Christensen AF, Sauter A, Bendtsen TF. Ultrasound guided transmuscular quadratus lumborum block. Br J Anaesth 2013; 111 (eLetters Suppl 22).

16. Dam M, Moriggl B, Hansen CK, Hoermann R, Bendtsen TF, Børglum $\mathrm{J}$. The pathway of injectate spread with the transmuscular quadratus lumborum block: A cadaver study. Anesth Analg 2017; 125:303-312.

17. Warusawitharana C, Basar HMS, Jackson LB, Niraj G. Ultrasound guided continuous transmuscular quadratus lumborum analgesia for open renal surgery: A case series. J Clin Anesth 2017; 42:100-101.

18. Serlin RC, Mendoza TR, Nakamura Y, Edwards KR, Cleeland CS. When is cancer pain mild, moderate or severe? Grading pain severity by its interference with function. Pain 1995; 61:277284.

19. Atkinson TM, Mendoza TR, Sit L, Passik S, Scher HI, Cleeland C, Basch E. The brief pain inventory and its "pain at its worst in the last 24 hours" item: Clinical trial endpoint considerations. Pain Med 2010; 11:337-346.

20. Dworkin RH, Turk DC, Wyrwich KW, Beaton D, Cleeland CS, Farrar JT, Haythornthwaite JA, Jensen MP, Kerns RD, Ader DN, Brandenburg N, Burke LB, Cella D, Chandler J, Cowan
P, Dimitrova R, Dionne R, Hertz S, Jadad AR, Katz NP, Kehlet $\mathrm{H}$, Kramer LD, Manning DC, McCormick C, McDermott MP, McQuay HJ, Patel S, Porter L, Quessy S, Rappaport BA, Rauschkolb C, Revicki DA, Rothman M, Schmader KE, Stacey BR, Stauffer JW, von Stein T, White RE, Witter J, Zavisic S. Interpreting the clinical importance of treatment outcomes in chronic pain clinical trials: IMMPACT recommendations. J Pain 2008; 9:105-121.

21. Devlin N, Parkin D, Browne J. Using the EQ-5D as a performance measurement tool in the NHS. Health Econ 2010; 19:886905.

22. Hebbard P. Subcostal transversus abdominis plane block under ultrasound guidance. Anesth Analg 2008; 106:674-675.

23. Niraj G, Kelkar A, Jeyapalan I, Graff-Baker P, Williams O, Darbar A, Maheshwaran A, Powell R. Comparison of analgesic efficacy of subcostal transversus abdominis plane blocks with epidural analgesia following upper abdominal surgery. Anaesthesia 2011; 66:465-471.

24. Niraj G, Kelkar A, Hart E, Horst C, Malik D, Yeow C, Singh B Chaudhri S. Comparison of analgesic efficacy of four-quadrant transversus abdominis plane (TAP) block and continuous posterior TAP analgesia with epidural analgesia in patients undergoing laparoscopic colorectal surgery: an open-label, randomised, non-inferiority trial. Anaesthesia 2014; 69:348-355.

25. Rozen WM, Tran TM, Ashton MW, Barrington MJ, Ivanusic JJ, Taylor GI. Refining the course of the thoracolumbar nerves: a new understanding of the innervation of the anterior abdominal wall. Clin Anat 2008; 21:325-333.

26. Porto M. A comparative trial of Botulinum toxin type $A$ and methylprednisolone for the treatment of myofascial pain syndrome from chronic muscle spasm. Pain 2000; 85:101-105. 
